\title{
Capsule Commentary on Radin, Pitfalls in Hemoglobin Alc Measurement: When Results May Be Misleading
}

\author{
Kenneth R. Feingold, MD \\ San Francisco VA Medical Center, University of California San Francisco, San Francisco, CA, USA.
}

J Gen Intern Med 29(2):363

DOI: $10.1007 / \mathrm{s} 11606-013-2632-9$

(c) Society of General Internal Medicine 2013

$\mathrm{T}$ he measurement of hemoglobin A1c (A1c) is the most common method used to determine glycemic control and is an important predictor of microvascular complications in patients with both type 1 and type 2 diabetes. ${ }^{1,2}$ Additionally, in 2010, the measurement of A1c was added as a criteria for the diagnosis of diabetes (A1c levels $\geq 6.5 \%$ indicate diabetes). ${ }^{3}$ Because of the importance of this laboratory test in both the diagnosis and management of patients with diabetes, it is essential that health care providers recognize the factors that can lead to inaccurate and misleading results. In this issue, Radin discusses in detail the potential pitfalls of Alc measurements and also provides guidance on how the clinician can use alternative tests to determine glycemic control. ${ }^{4}$ The level of A1c is dependent on both the concentration of plasma glucose and the duration of exposure of hemoglobin to glucose. ${ }^{5}$ Thus, one major artifact of A1c measurements is changes in the half-life of red blood cells (RBC). Disorders that lead to an increased percentage of older RBCs, such as iron deficiency anemia, B12 or folate deficiency, or asplenia, artifactually elevate A1c levels. Conversely, disorders that shorten RBC life span, such as hemolytic anemia, blood loss, and splenomegaly, artifactually lower A1c levels. Patients with end-stage renal disease typically have falsely low Alc levels, due to a decrease in $\mathrm{RBC}$ lifespan. Similarly, during pregnancy, RBC lifespan is decreased leading to decreased A1c levels. Finally, hemoglobin variants can result in artifactually increased or decreased A1c levels, depending on the specific variant and the method used to measure A1c levels. In the article by Radin, more complete information on the variety of factors that can alter Alc measurements is provided. It is important to recognize that there are other methods for determining glycemic control, including measuring fructosamine, glycated albumin, 1,5anhydroglucitrol, and continuous glucose monitoring. In patients with disorders that affect A1c measurements, these alternative tests are useful for determining glycemic control. Additionally, these alternative tests are very helpfu when home blood glucose measurements and A1c levels are discordant.

Conflict of Interest: The author declares that he does not have a conflict of interest.

Corresponding Author: Kenneth R. Feingold, MD; San Francisco VA Medical Center, University of California San Francisco, 4150 Clement St, San Francisco, CA 94121, USA (e-mail: Kenneth.feingold@ucsf.edu).

\section{REFERENCES}

1. The Diabetes Control and Complications Trial Research Group. The effect of intensive treatment of diabetes on the development and progression of long-term complications in insulin-dependent diabetes mellitus. N Engl J Med. 1993;329:977-86.

2. UK Prospective Diabetes Study (UKPDS) Group. Intensive blood-glucose control with sulphonylureas or insulin compared with conventional treatment and risk of complications in patients with type 2 diabetes (UKPDS 33). Lancet. 1998;352:837-53.

3. American Diabetes Association. Diagnosis and Classification of diabetes mellitus. Diabetes Care. 2010;33(Suppl 1):S62-9.

4. Radin MS. Pitfalls in hemoglobin Alc measurement: when results may be misleading. J Gen Intern Med. 2013. doi:10.1007/s11606-013-2595-x.

5. Spicer KM, Allen RC, Hallett D, Buse MG. Synthesis of hemoglobin Aic and related minor hemoglobin by erythrocytes. In vitro study of regulation. J Clin Invest. 1979;64:40-8. 